\title{
Physical activity and health: Shifting focus from modern era to Stone Age life style
}

\author{
Vikram Mohan $^{1 *}$ and Kesavanarayanan Krishnan Selvarajan ${ }^{2}$ \\ ${ }^{1}$ Department of Physiotherapy, Faculty of Health Sciences, Universiti Teknologi MARA, Puncak Alam Campus, 42300 Puncak Alam, Selangor, Malaysia \\ ${ }^{2}$ Department of Pharmacology and Toxicology, College of Pharmacy, Hail University, Hail, Saudi Arabia
}

\begin{abstract}
Transition from Paleolithic lifestyle to sedentary lifestyle has lead to the development of several lifestyle diseases worldwide. Regular physical activity is essential to improve or maintain our health. Physical inactivity and increased sedentary lifestyle are one among the major threats to the present and future health. Several studies revealed both physical activity and healthy diet are equally essential to both human and animal's health. Specialists recommend physical activity in the prevention/ treatment of several health disorders since it is cost effective with fewer side effects compared to synthetic medicines. This article attempts to explore the beneficial effects of physical activity learnt through some of the research experiments. A closer look into the lifestyle of our ancestors will provide more benefit to humankind.
\end{abstract}

\section{Introduction}

Physical activity is essential in life to stay healthy and maintain our normal behavior. Physical activity is defined as any bodily movement produced by skeletal muscles that require energy expenditure. It should not be mistaken with "exercise", which is a subcategory of physical activity. A number of studies from animals to humans revealed the benefits of physical exercise for various health disorders. This paper discusses the lifestyle practices and food which was practiced during Stone Age and the reasons for physical inactivity in the modern era. In addition, the metabolic health benefits of physical exercise learnt through animals and human experiments have been discussed.

\section{Stone age: Paleolithic lifestyle}

During Paleolithic (palaios: old; lithos: stone) era people used stone to make their tools to meet basic needs for food, shelter, and clothing. The physical activity of old stone age people depends on their ability to hunt or gather food, produce water, build and maintain clothing and shelter, escaping from predators and enjoying social interaction. Barefoot walking had strengthened their muscles, tendons and general co-ordination, reducing the possibility of developing acute/chronic health disorders. They prepare their healthy balanced diet preferably from natural sources which are minimally processed. Therefore, the contribution of both energy intake and expenditure turned balanced and is a vital component to maintain their health. It was estimated that one-third of their energy intake was spent on physical activity.

Intermittent fasting was practiced by our ancestors and few groups of people till date, which significantly helped to control the variety of health indicators including glucose, cholesterol, triglycerides and other metabolites. Regular exposure of skin to sunlight is necessary to produce vitamin $\mathrm{D}$, which boosts the immune system, prevents cancer and aids in bone growth/repair. Lack of (sun) light has also been shown to be a cause of depression and lack of sunlight during winter results in reduced Vitamin D synthesis and immunity leading to onset of "flu" during this season. Cold baths have shown to enhance the immune system and hot baths promote the release of "heat shock proteins" that protect and repair damage in the body's cells. All the above said factors are accomplished in those days.

\section{Modern era: Sedentary lifestyle}

In the modern era, advancement in technology has directed us to lead sedentary lifestyle and has resulted in marked decline in our regular physical activity and food habits compared to the Paleolithic life style. Physical inactivity over a longer period of time has been identified as a risk factor for the development of non-communicable diseases such as heart disease, diabetes, cancer and obesity. The major reasons for physical inactivity are due to insufficient participation in physical activity, sedentary lifestyle and increased use of passive modes of transport. Increased urbanization such as violence, heavy traffic, air pollution, lack of parks, sidewalks and sports/recreation facilities are also considered to be the major reasons for the decline in physical activity. Physical inactivity tends to increase with age and sedentary lifestyles are more likely to be lead by females than men. The sedentary life style has high calorie rich diets such as grain and milk based foodstuffs, sugars, vegetable oils, processed foods with additives that may interfere with their metabolism. These foods also contain easily digestible carbohydrates which increase the glucose levels in blood and further stored as fat by the action of insulin. Chronic intake of such foods could lead to metabolic disorders.

\section{Companion animals and human well-being}

Companion animals could improve the health of their owners and may contribute to their well-being [1]. Pets could potentially encourage the participation of their owners through walking and

Correspondence to: Vikram Mohan, Department of Physiotherapy, Faculty of Health Sciences, Universiti Teknologi MARA, Puncak Alam Campus, 42300 Puncak Alam, Selangor, Malaysia, E-mail: vikkipt@gmail.com

Key words: physical activity, physical inactivity, exercise, companion animals, health, paleolithic and sedentary lifestyle

Received: March 28, 2017; Accepted: April 22, 2017; Published: April 25, 2017 
thereby act as an agent for improving physical activity and change in their lifestyle [2]. Pet walking have improved the children's physical activities; among obese children's [3,4] and elderly [5]. Pet-assisted therapy for hospitalized children's with cancer has alleviated their emotional distress, facilitated their adaptation to the healing process and promoted their well-being [6]. Pet-assisted therapy on trauma symptoms for sexually abused children's have shown to decrease their trauma symptoms such as anxiety, depression, anger, post-traumatic stress disorder, dissociation, and sexual concerns [7]. Non-pet walkers are self-reported to possess risk indicators that may lead to diabetes mellitus, hypertension, hypercholesterolemia and depression compared to dog walkers [8]. Owing a pet ownership have improved the physical activity, demonstrated life prolonging effects among heart attack sufferers [9] and elderly patients after myocardial infarction [10].

\section{Lessons from pre-clinical and clinical research}

Regular exercise training has shown beneficial anti-atrophy effects [11] in diabetic rats and improved skeletal muscle insulin resistance in obese Zucker rat rats [12]. Animal models were used to study the exercise-mediated effects on the regulation of lipid metabolism using guinea pigs [13]. Enhancement of neuronal differentiation and deteriorated motor function was observed in Parkinson's rats subjected to exercise [14]. The intensity of myocardial infarct size after was reduced after subjecting coronary artery occluded rats to forced swim test and this reduction may be correlated to increased myocardial vascularity [15]. It is evident from the above studies; exercise has positive effects to both normal subjects and subjects with altered pathophysiology.

Similarly several studies on humans also revealed the exercise has potential benefits to maintain their health and fitness. Extensive epidemiological evidence demonstrates that mild physical exercise without weight loss can be adopted as an adjunct approach in the treatment of diabetes mellitus. It increases the rate of glucose uptake into the skeletal muscles by over-expression of glucose transporter, GLUT4 to the plasma membrane [16,17]. Scientific reports have linked that regular physical exercise to various risk factors for cardiovascular disease. It promotes weight reduction, thereby reduces the blood pressure. It also the reduces the low-density lipoprotein, total cholesterol, and increase the high-density lipoprotein level in the blood [18]. Hypertensive subjects are physically inactive compared to normal subjects and studies support that hypertensive individuals need to optimize blood pressure by practicing regular exercise [19]. Chronic systemic inflammation is associated with the development of obesity and metabolic dysfunction. During obesity, increased secretion of pro-inflammatory cytokines (adipokines) from adipocytes (fat cells) [20] is accompanied by insulin resistance and glucose intolerance. Mild to chronic exercise have shown to ameliorate both dyslipidemia and systemic inflammation [21]. Physical exercise might benefit obese partly through increased secretion of anti-inflammatory adipokines and decreased production of pro-inflammatory cytokines [22]. It has also been hypothesized that exercise promotes adipocyte oxidative capacity [23].

\section{Closing comment}

Its clear form the above a change in life style could keep us healthier in the modern computer world. A closer look into the Paleolithic lifestyle lead by our ancestor's revealed that balanced physical activity along with nutritious diets have helped them to stay metabolically healthy. People living sedentary life style must look into Paleolithic lifestyle which might provide the answers to keep them healthy and lead a better future. Patients with health disorders should seek the advice of physicians and health care professionals to know their food habits and get prescribed with appropriate exercises which could provide additional benefit to maintain health.

\section{References}

1. Wells DL (2009) The Effects of Animals on Human Health and Well-Being. Journal of Social Issues 65: 523-543.

2. Gretebeck KA, Radius K, Black DR, Gretebeck RJ, Ziemba R, et al. (2013). Dog ownership, functional ability, and walking in community-dwelling older adults. $J$ Phys Act Health 10: 646-655. [Crossref]

3. Christian H, Trapp G, Lauritsen C, Wright K, Giles-Corti B (2013) Understanding the relationship between dog ownership and children's physical activity and sedentary behaviour. PediatrObes 8: 392-403. [Crossref]

4. Wohlfarth R, Mutschler B, Beetz A, Kreuser F, Korsten-Reck U (2013) Dogs motivate obese children for physical activity: key elements of a motivational theory of animalassisted interventions. Front Psychol 4: 796. [Crossref]

5. Scheibeck R, Pallauf M, Stellwag C, Seeberger S (2011) Elderly people in many respects benefit from interaction with dogs. Eur J Med Res 16: 557-563.[Crossref]

6. Gagnon J, Bouchard F, Landry M, Belles-Isles M, Fortier M, et al. (2004)Implementing a hospital-based animal therapy program for children with cancer: a descriptive study. Can Oncol Nurs $J$ 14: 217-222. [Crossref]

7. Dietz TJ, Davis D, Pennings J (2012) Evaluating animal-assisted therapy in group treatment for child sexual abuse. J Child Sex Abus 21: 665-683. [Crossref]

8. Lentino C, Visek AJ, McDonnell K, DiPietro L (2012) Dog walking is associated with a favorable risk profile independent of moderate to high volume of physical activity. $J$ Phys Act Health 9: 414-420. [Crossref]

9. Levine GN, Allen K, Braun LT, Christian HE, Friedmann E, et al. (2013) Pet ownership and cardiovascular risk: a scientific statement from the American Heart Association. Circulation 127: 2353-2363. [Crossref]

10. Ruzić A, Miletić B, Ruzić T, Persić V, Laskarin G (2011)Regular dog-walking improves physical capacity in elderly patients after myocardial infarction. CollAntropol 35: 7375.[Crossref]

11. Chen GQ, Mou CY, Yang YQ, Wang S, Zhao ZW(2011) Exercise training has beneficial anti-atrophy effects by inhibiting oxidative stress-induced MuRF1 upregulation in rats with diabetes. Life Sci 89: 44-49. [Crossref]

12. Willems ME, Brozinick JT Jr, Torgan CE, Cortez MY, Ivy JL (1991) Muscle glucose uptake of obese Zucker rats trained at two different intensities. J ApplPhysiol (1985)70: 36-42. [Crossref]

13. Ensign WY, McNamara DJ, Fernandez ML (2002) Exercise improves plasma lipid profiles and modifies lipoprotein composition in guinea pigs. J NutrBiochem 13: 747753. [Crossref]

14. Tajiri N, Yasuhara T, Shingo T, Kondo A, Yuan W, et al. (2010). Exercise exerts neuroprotective effects on Parkinson's disease model of rats. Brain Res 1310: 200-207. [Crossref]

15. McElroy CL, Gissen SA, Fishbein MC. (1978). Exercise-induced reduction in myocardial infarct size after coronary artery occlusion in the rat. Circulation57: 958 962. [Crossref]

16. Goodyear LJ, Kahn BB (1998) Exercise, glucose transport, and insulin sensitivity Annu Rev Med 49: 235-261.[Crossref]

17. Holloszy JO (2005) Exercise-induced increase in muscle insulin sensitivity. $J$ ApplPhysiol (1985) 99: 338-343.[Crossref]

18. Myers J (2003) Cardiology patient pages. Exercise and cardiovascular health Circulation 107: e2-5.[Crossref]

19. Sharman JE, La Gerche A, Coombes JS (2015) Exercise and cardiovascular risk in patients with hypertension. Am J Hypertens28: 147-158.[Crossref]

20. You T, Arsenis NC, Disanzo BL, Lamonte MJ. (2013) Effects of exercise training on chronic inflammation in obesity: current evidence and potential mechanisms. Sports Med 43: 243-256. [Crossref]

21. Lira FS, Rosa Neto JC, Antunes BM, Fernandes RA (2014) The Relationship between Inflammation, Dyslipidemia and Physical Exercise: from the Epidemiological to Molecular Approach. Curr Diabetes Rev 10:391-6. [Crossref]

22. Golbidi S, Laher I (2014) Exercise Induced Adipokine Changes and the Metabolic Syndrome. J Diabetes Res. [Crossref]

23. Park YM, Myers M, Vieira-Potter VJ (2014) Adipose tissue inflammation and metabolic dysfunction: role of exercise. Mo Med 111: 65-72. [Crossref]

Copyright: (C2017 Mohan V. This is an open-access article distributed under the terms of the Creative Commons Attribution License, which permits unrestricted use, distribution, and reproduction in any medium, provided the original author and source are credited. 